\title{
Transposed brachio-basilic arterio-venous fistulae versus prosthetic arterio- venous grafts; mid-term results and a review of literature
}

\author{
Nalaka Gunawansa ${ }^{1,2}$, Bernhard Wolf ${ }^{2,3}$ \\ 1. National Institute of Nephrology Dialysis and Transplant, Sri Lanka \\ 2. University of Edinburgh, United Kingdom \\ 3. Raigmore Hospital, Inverness, United Kingdom
}

Key words : Renal dialysis; central venous catheters; arteriovenous fistula; kidney failure chronic; axillary veins

\begin{abstract}
\section{Introduction}

With increasing prevalence of chronic kidney disease worldwide, the demand for long-term renal replacement therapy is on the incline. Apart from renal transplantation, this includes sustainable vascular access for long-term haemodialysis, often requiring secondary and tertiary access.
\end{abstract}

\section{Objective}

To assess the place of Transposed Brachio-Basilic ArterioVenous Fistula (TBB-AVF) as a second line access compared to prosthetic Aretrio Venous Grafts (AVG), with emphasis on functional patency and access related morbidity and mortality.

\section{Study Design}

A prospective cohort study (January 2014 to March 2016) comparing TBB-AVF and AVG, at the National Institute of Nephrology Dialysis and Transplantation, Colombo, Sri Lanka.

All patients where venous mapping revealed no suitable cephalic vein were included. Those who preferentially opted for a central venous catheter, those requiring urgent initiation of dialysis or considered unfit for TBB-AVF or AVG creation were excluded. TBB-AVF was performed where the basilic vein was patent and $>2 \mathrm{~mm}$. AVG was used when it was $<2 \mathrm{~mm}$ or when haemodialysis was expected to commence within 4 weeks.

\section{Results}

459 patients were enrolled; 382(83\%) TBB-AVF and $77(17 \%)$ AVG. Mean follow-up was $11( \pm 4.8)$ months.

Correspondence: Nalaka Gunawansa

E-mail: vascular@drnalakagunawansa.com

Received: 05-08-2017 Accepted: 24-08-2017

(iD) http://orcid.org/ 0000-0003-0098-3855

DOI: http://doi.org/10.4038/sljs.v35i2.8382

The Sri Lanka Journal of Surgery 2017; 35(2): 7-15
There were 9 deaths, all $>4$ weeks from access creation and not directly related to the access. The all-cause mortality rate was 5/382 (1.3\%) TBB-AVF and 4/77 (5.2\%) AVG; $\mathrm{p}=0.02$. Surgical site infections were seen in 24 (6.4\%) TBB-AVFs and $10(13.7 \%)$ AVGs; $p=0.03$. The overall functional patency at six months was $307 / 375(81.9 \%)$ in TBB-AVF and 57/73 $(78.1 \%)$ in AVGs; $p=0.45$.

\section{Conclusion}

TBB-AVF provide comparable medium term functional patency to AVG and are associated with a significantly less incidence of all-cause mortality and surgical site infection.

\section{Introduction}

The global incidence and prevalence of End Stage Kidney Disease (ESKD) has shown a general upward trend. Although data from England show stable numbers [1], the trend in other regions including South Asia, United States and Australasia is a steady increase [2-5]. This, coupled with increased life expectancy places a constant demand for renal replacement therapy [6]. Although transplantation is the best solution for ESKD [7], the scarcity of organs is a global problem [8], resulting in an ever-expanding pool of patients requiring long-term dialysis and options for vascular access [9].

Haemodialysis requires access via an Autologous ArterioVenous Fistula (AAVF), Arterio-Venous Graft (AVG) or a Central Venous Catheter (CVC). AAVF is considered the optimum vascular access due to long-term durability and minimum morbidity [10-12]. The preferred vein for primary AAVF is the cephalic vein at the anatomical snuff-box or antecubital fossa $[13,14]$. When the cephalic vein is not available, there has been a general inclination to use CVC or AVG, ahead of 'second line' AAVF options such as Transposed Brachio-Basilic fistula (TBB-AVF) $[15,16]$.

\section{Background}

Despite global recommendations and the 'Fistula-First Breakthrough Initiative'[9], the use of TBB-AVF over AVG as a second-line vascular access has been modest [17]. AVG 
involve the use of prosthetic grafts with inherent risks of infection and thrombosis [18-20], in addition to the escalated costs of grafts and associated possible re-interventions to maintain patency $[20,21]$.

The basilic vein lies in a deeper plane than the cephalic, hence being spared from routine cannulation. It is anatomically wider than the cephalic, making it more suitable for AAVF creation. However, its deep location and proximity to the neuro-vascular bundle make it unsuitable for regular cannulation in-situ. This is circumvented by either superficialization or transposition of the vein away from its natural lie [22-24]. Both procedures require general or regional anaesthesia and extended dissection with the possibility of wound related complications; making it a less popular option for vascular access.

'Superficialization' involves dissecting the vein along its path, ligating the tributaries, bringing it superficial to the fascia and suturing the fascia underneath the fistula $[22,25]$. However, this places the fistula directly underneath the surgical scar causing increased pain during cannulation. 'Transposition' takes the vein away from its natural path altogether, superficial to the fascia and lateral to the harvesting incision [22, 26] (Figure 1). Transposition can be performed as a single-stage operation where the superficial tunneling and anastomosis of the vein is all done in one sitting. Alternatively, it can be performed in two stages; first stage involving a brachio-basilic anastomosis at the cubital fossa, followed by an interval of 4-6 weeks for maturation and a second stage of lateral transposition [27]. Studies have not shown a significant clinical difference in outcomes between primary or staged transposition [28, 29].

\section{Aims}

Although the place of TBB-AVF has been studied previously $[22,30]$, there is limited data comparing its efficacy compared to AVG [31-34]. The existing studies are mostly retrospective with only one prospective multicenter trial [35]. Aim of this study was to prospectively compare outcomes of TBB-AVF and AVG in terms of patency for dialysis, mean flow rates, reintervention rate and associated morbidity or mortality.

Primary patency was defined as satisfactory patency demonstrated on Duplex Ultra Sound (DUS). Primary assisted patency was defined as patency 'maintained' by secondary interventions (fistuloplasty, thrombectomy). Secondary patency was defined as patency 're-established' after early thrombosis. Functional patency was defined as sustained patency with successful use in haemodialysis.

\section{Study design}

This was a prospective, non-randomized cohort study of all vascular access performed at the Vascular Surgical Unit of
National Institute of Nephrology, Dialysis and Transplantation (NINDT), Sri Lanka from January 2014 to March 2016. Although there are over 12 centers providing vascular access services in Sri Lanka, NINDT is the only 'dedicated' center for Nephrology and Vascular access, where approximately 30\% of procedures are for referrals of previously failed access procedures. NINDT Vascular surgical unit comprises of a single specialist vascular surgeon and support staff, with the specialist surgeon performing all access operations, averaging 25 procedures per week.

The selection of access site was based on National Kidney Foundation (NKF)-Kidney Disease Outcomes Quality Initiative (KDOQI) guidelines [11]. All patients underwent preliminary clinically assessment and DUS vein mapping. Clinical assessment included examination of potential veins, overlying skin, arterial pulse, blood pressure and ability to exercise the hand. DUS vein mapping was done by a trained vascular radiologist or surgeon in accordance with accepted guidelines [36]. A viable cephalic vein $>2 \mathrm{~mm}$ at the wrist or $>3 \mathrm{~mm}$ at the elbow, assessed without a tourniquet, was considered the first preference.

All patients in whom DUS revealed no suitable cephalic vein in either arm were included in the study. After initial assessment and counselling, those who preferentially requested a tunneled $\mathrm{CVC}$ over an AVF were excluded. Furthermore, patients who 'crash-landed' to hospital requiring urgent CVC for immediate use and those who were deemed medically unfit for anaesthesia to carry out TBB-AVF or AVG creation were also excluded.

TBB-AVF was attempted in all who had a patent basilic vein $>2 \mathrm{~mm}$ without a tourniquet. AVG was used when no suitable basilic vein was seen or when it was presumed that haemodialysis would be initiated within 4 weeks of access creation. All AVG used Expanded Polytetrafluoroethylene (ePTFE Jotec ${ }^{\circledR}$ ) grafts with a wall thickness of $0.5 \mathrm{~mm}$ and internal diameter of $6 \mathrm{~mm}[37,38]$. In TBB-AVF, basilic vein transposition was done in preference to superficialization, as the standard practice in the unit. Primary transposition was done when the vein diameter was $>4 \mathrm{~mm}$, while all others had staged transposition after 4-6 weeks. General anaesthesia or sedation was used in all second stage transpositions, primary transpositions and AVG creations. All transposition and AVG were covered by 3 doses of prophylactic intravenous antibiotics (cefuroxime or co-amoxiclav). Intra-operative heparin 5000 IU was given 2 minutes prior to arterial clamping. Post-operative Aspirin $75 \mathrm{mg}$ daily was used unless medically contra-indicated.

The arterial inflow was the brachial artery at the cubital fossa. In AVG, venous outflow was the axillary vein approached via a trans-axillary incision. All anastomoses used 7/0 polypropylene continuous suture with an end-to side 
configuration. All TBB-AVF were actively encouraged on isometric hand-arm exercises at each planned patient contact $[39,40]$.

Primary and primary assisted or secondary patency was assessed by DUS and defined as an uninterrupted flow rate of $>600 \mathrm{ml} / \mathrm{min}$. Functional patency was defined as the successful use in haemodialysis with a flow rate of $>600$ $\mathrm{ml} / \mathrm{min}$ without significant recirculation, sustaining dialysis for 4 hours $[41,42]$.

All patients were followed up with DUS at 1, 4, 8 and 12 weeks and whenever clinically indicated thereafter [17]. DUS was done using HDI 5000 (Philips Healthcare, USA) machine with a $7.5 \mathrm{MHz}$ linear transducer. Flow rate measurements were done using doppler quantitative colour flow measurement [43, 44] before dialysis initiation and Transonic ${ }^{\circledR}$ (Transonic systems Inc. USA) ultra-sound dilution technique after initiation [45-47]. Patency assessments were done within the first hour of initiating dialysis before the onset of significant fluid shifts.

Any stenosis on DUS or persistent high venous pressures during haemodialysis were evaluated by fistulogram. Delayed maturation of TBB-AVF with a flow $<400 \mathrm{ml} / \mathrm{min}$ at 6 weeks post-surgery was also referred for fistulogram [10]. Any significant stenosis confirmed on fistulogram was managed by surgical or endovascular fistuloplasty. Mechanical stents were not used due to unavailability. Surgical thrombectomy was performed wherever there was partial or complete thrombosis and when it was deemed salvageable. Successful thrombectomy was followed by oral anticoagulation for 4 weeks in addition to aspirin.

Surgical Site Infections (SSI) and other complications were documented and categorized according to the Clavien-Dindo [48], Accordion [49] classification systems. They were categorized as minor (requiring out-patient wound care), moderate (requiring admission, intra-venous antibiotics), severe (requiring admission, intravenous antibiotics, surgical drainage, exploration and/or having systemic sepsis) and death (access surgery related death). The incidence of access related 'steal syndrome' with distal ischaemia was also studied. The preferred option for management of limb threatening 'steal' was Distal Revascularization and Interval Ligation (DRIL) [50,51], using autologous great saphenous vein.

All data was collected prospectively using a computerized database in a Microsoft excel worksheet (Microsoft, USA). Analysis was done using SPSS for Windows, software version 21.0 (SPSS Inc., USA) [52]. Continuous data was described as means ( \pm standard deviation) and compared using student $t-$ test. Categorical data was described as percentages and compared using the Pearson's Chi-square test. A p value of
$<0.05$ was considered statistically significant.

\section{Results}

There were 2089 consecutive vascular access procedures during this period. Among them, 541 were eligible for the study after initial assessment. 82 were subsequently excluded; 21 preferentially opting for peritoneal dialysis, 19 considered medically unfit and referred for tunneled CVC and 42 referred for CVC due to patient preference or urgency of haemodialysis. 459 patients were finally enrolled (Figure 2). Among them, 382 (83\%) had TBB-AVF while the remaining

\begin{tabular}{|l|l|l|l|}
\hline Baseline Characteristics & $\begin{array}{l}\text { TBB -AVF } \\
\text { N=382 }\end{array}$ & $\begin{array}{l}\text { AVG } \\
\text { N=77 }\end{array}$ & $\begin{array}{l}\text { P } \\
\text { value }\end{array}$ \\
\hline $\begin{array}{l}\text { Gender } \\
\text { Male, number (\%) }\end{array}$ & $183(48 \%)$ & $36(47 \%)$ & 0.91 \\
Female, number (\%) & $199(52 \%)$ & $41(53 \%)$ & \\
\hline Age & $218(57 \%)$ & $37(48 \%)$ & 0.16 \\
\hline < 40 yrs. & $164943 \%)$ & $40(52 \%)$ & \\
\hline 40 yrs. and over & $186(49 \%)$ & $29(38 \%)$ & 0.08 \\
\hline Co-morbidities & $63(16 \%)$ & $14(18 \%)$ & 0.73 \\
\hline Diabetes & $123(32 \%)$ & $26(34 \%)$ & 0.79 \\
Peripheral Vascular dis. & $259(68 \%)$ & $51(66 \%)$ & \\
\hline Access type & Primary access & &
\end{tabular}

Table 1. The baseline characteristics of the two groups

77 (17\%) who had no viable basilic vein on DUS, had AVG creation.

The baseline characteristics of the two groups including gender, age, presence of diabetes mellitus and peripheral vascular disease were comparable (Table-1).

The mean follow-up was $11( \pm 4.8)$ months. Follow up data at six months was considered for comparison. There were 9 deaths during the first six months, all occurring beyond 4 weeks and not directly related to access surgery. The causes of death were myocardial infarction (05), left ventricular failure (02) and pneumonia (02). The all-cause mortality rate was $5 / 382(1.3 \%)$ in the TBB-AVF group and $4 / 77(5.2 \%)$ in the AVG group, with statistical significance at a $\mathrm{p}$ value of 0.02 . Two patients with TBB-AVF migrated overseas within the first six months and were lost to surveillance. Calculated sixmonth follow up data was complete in 448 (375 TBB-AVF, 73 AVG) patients (97.6\%).

Among the TBB-AVF, 23 were found to have stenotic segments or partial thrombosis during surveillance. Fifteen such fistulae were salvaged successfully by fistuloplasty or thrmobectomy, achieving satisfactory primary assisted patency. A further 49 fistulae demonstrated poor maturation [36] or complete thrombosis [13] and were considered unusable. These, along with the 08 fistuale that re-thrombosed despite initial thrombectomy, required alternate access with 


\section{AVG or CVC.}

Seventeen AVG showed evidence of intra-luminal thrombi

\begin{tabular}{|l|l|l|c|}
\hline & TBB-AVF & \multicolumn{1}{|c|}{ AVG } & $\begin{array}{c}\text { P } \\
\text { value }\end{array}$ \\
\hline All-cause mortality & $\begin{array}{l}5 / 382 \\
=1.3 \%\end{array}$ & $\begin{array}{l}4 / 77 \\
=5.2 \%\end{array}$ & 0.02 \\
\hline Primary patency & $\begin{array}{l}303 / 375 \\
=80.8 \%\end{array}$ & $\begin{array}{l}56 / 73 \\
=76.7 \%\end{array}$ & 0.42 \\
\hline $\begin{array}{l}\text { Primary assisted/ } \\
\text { secondary patency }\end{array}$ & $\begin{array}{l}318 / 375 \\
=84.8 \%\end{array}$ & $\begin{array}{l}61 / 73 \\
=83.6 \%\end{array}$ & 0.78 \\
\hline Functional patency & $\begin{array}{l}307 / 375 \\
=81.9 \%\end{array}$ & $\begin{array}{l}57 / 73 \\
=78.1 \%\end{array}$ & 0.45 \\
\hline Mean flow rate & $733 \mathrm{ml} / \mathrm{min}$ & $749 \mathrm{ml} / \mathrm{min}$ & 0.11 \\
\hline $\begin{array}{l}\text { Surgical Site } \\
\text { Infection (SSI) }\end{array}$ & $\begin{array}{l}24 / 375 \\
=6.4 \%\end{array}$ & $\begin{array}{l}10 / 73 \\
=13.7 \%\end{array}$ & 0.03 \\
\hline Haematoma & $\begin{array}{l}19 / 375 \\
=5 \%\end{array}$ & $\begin{array}{l}4 / 73 \\
=5.4 \%\end{array}$ & 0.88 \\
\hline Re-intervention & $\begin{array}{l}23 / 375 \\
=6.1 \%\end{array}$ & $\begin{array}{l}7 / 73 \\
=9.6 \%\end{array}$ & 0.28 \\
\hline
\end{tabular}

Table 2. Comparison of Results

during DUS surveillance. Ten such AVGs presented late with associated SSI or significant inflammation, requiring graft explantation. Five had successful thrombectomy and anticoagulation going on to demonstrate sustained secondary patency. Two AVG re-thrombosed after initial thrombectomy and were referred for tunneled CVC as alternate access.

The comparison (Table-2)

The overall patency rates between the two groups did not show any significant difference. Primary patency rates for TBB-AVF and AVG were 303/375 (80.8\%) and 56/73 $(76.7 \%)$ respectively, $p=0.42$. The primary assisted or secondary patency rates were $318 / 375(84.8 \%)$ and $61 / 73$ (83.6\%), $\mathrm{p}=0.78$ while the functional patency was $307 / 375$ $(81.9 \%)$ and $57 / 73(78.1 \%)$ respectively, $\mathrm{p}=0.45$. The mean flow rate on DUS was $733( \pm 147) \mathrm{ml} / \mathrm{min}$ and $749( \pm 118)$ $\mathrm{ml} / \mathrm{min}$ for TBB-AVF and AVG respectively, with no significance in the difference $(\mathrm{p}=0.11)$.

There were no documented anastomotic or puncture-site pseudo aneurysms during the study period. SSI was seen in 24 TBB-AVF $(24 / 375,6.4 \%)$ and 10 AVG $(10 / 73,13.7 \%)$, with statistical significance $(p=0.03)$. Four of these TBB-AVF progressed to thrombosis and eventual failure while the remaining 20 were successfully managed by local wound care and antibiotics. All 10 AVGs that demonstrated significant infection were explanted.

Surgical site haematoma formation was seen in $19 \mathrm{TBB}-\mathrm{AVFs}$ $(5 \%)$ and $04 \mathrm{AVGs}(5.4 \%)$, with no statistical significance at a $\mathrm{p}$ value of 0.88 . Two TBB-AVF related haematomas required surgical evacuation due to fistula compression. Minor haematoms with no compressive features were managed

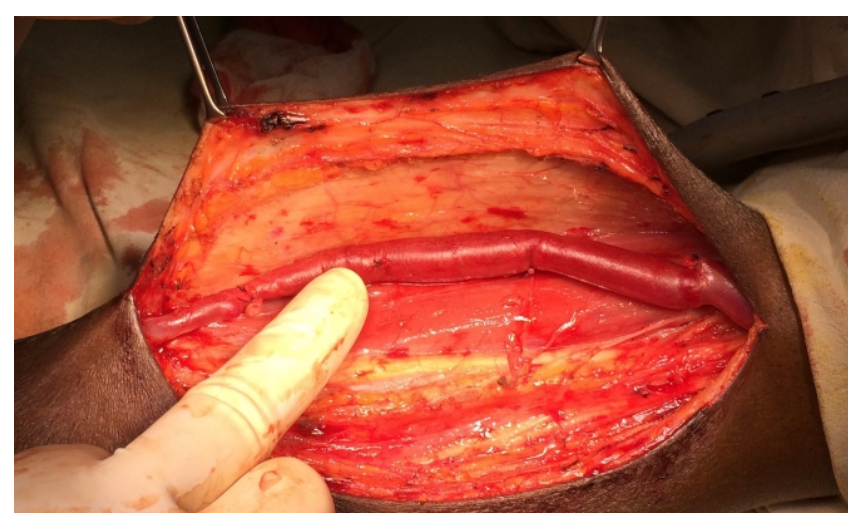

Figure 1.

conservatively. Clinically significant 'steal' with digital ischaemia was seen in one patient (TBB-AVF, 4 months after creation), requiring a DRIL procedure and index finger amputation. The re-intervention rate to maintain or reestablish patency was 23/375 (6.1\%) for TBB-AVF and 7/73 (9.6\%) for $A V G$, with no statistical significance $(\mathrm{p}=0.28)$.

\section{Discussion}

The 'Fistula-first breakthrough initiative' of the NKF and its recommendations were aimed at achieving early referral for access creation. It aimed at $66 \%$ vascular access by AAVF [53-55] and at least $70 \%$ of new dialysis initiations to be via AAVF. Nevertheless, the results have fallen well below these targets with late referrals and sustained use of AVG and CVC [9]. Therefore, the exact place of TBB-AVF in the treatment algorithm where cephalic vein access in not achievable, is still somewhat controversial [21].

Many of the existing studies concerning AVG and its role in long-term haemodialysis are retrospective $[22,23,56]$ with only one prospective multicenter trial comparing AVG to TBB-AVF [35]. In summary, these studies found that while AVG provided comparable access patency, they carried higher rates of all-cause mortality, morbidity, re-intervention, readmission and overall institutional costs.

An AAVF is preferable for long-term haemodialysis due to its durability, minimal risk of thrombosis and infection as well as cost-effectiveness $[57,58]$. The reported 1-year functional patency in brachio-cephalic fistula is $70-91 \%$ [59, 60]. Early reports of basilic fistulae reported poor patency rates at 50$60 \%[61,62]$. However, with protocol-based surveillance and early intervention for stenoses, the functional patency rate of TBB-AVF has increased remarkably, reaching up to $90 \%$ and comparable to brachio-cephalic fistulae [27, 59, 63]. In comparison, the 1-year patency rates of AVG have remained comparatively low around 50-70\% [59].

Our results showed comparable primary, primary assisted or secondary patency and functional patency rates for TBB-AVF and AVG. Although our patency rates were for 6 months, 


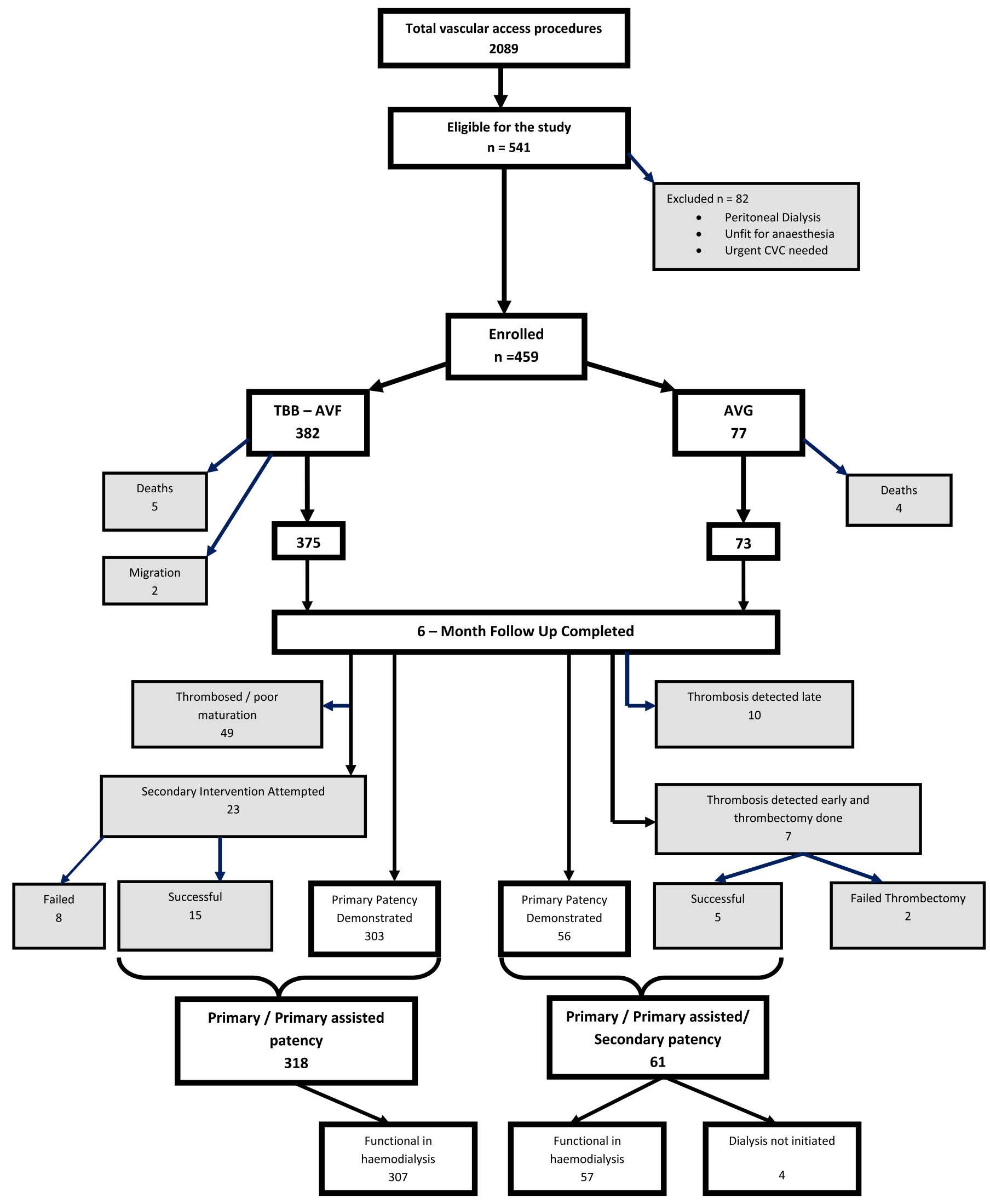

Figure 2. 
having a centralized database and surveillance system, being the only designated hospital for renal care and being an island with a relatively small geographical distribution contributed to our very small drop-out rate. Most of the existing literature for TBB-ABF and AVG showed inherent differences in patient characteristics, with a general inclination of AVG in females, older patients and those with diabetes [64]. Our study comprised a wide cross section of patients from the entire country, where the baseline characteristics were largely comparable (Table-1).

The single most important factor attributed to poor long-term patency in AVGs is neo-intimal hyperplasia at the anastomotic site [65]. This is thought to be caused by shear-stress injury at the venous anastomotic site due to turbulent flow and intimal trauma. Numerous improvisations have been attempted to minimize this with limited success, including use of a venous cuff [66] and staples or nitinol clips instead of sutures $[67,68]$. However, there are no randomized control trials to demonstrate any compelling evidence of their superiority over standard end to side anastomosis using polypropylene sutures used in our study.

The most commonly used material for AVG is expanded polytetrafluoroethylene (ePTFE). Over the last two decades, numerous modifications have been introduced to increase patency, reduce thrombosis and infection, including heparin bonding, and antibiotic impregnation. Although showing certain advantages such as the ability for early cannulation, there is paucity of robust data to prove superiority of one material over the other $[69,70]$.

Access flow rates can be measured in various ways including direct doppler quantitative measurement and the indirect ultra-sound dilution technique. Direct doppler quantitative testing is quick, non-invasive and simple, although carrying significant operator variability and bias based on operator experience and angle of the doppler probe [45]. Ultra sound dilution measurement is considered the 'gold standard' [45, $46]$, as it excludes operator variability and is more objective. However, this involves invasive testing and thereby is useful only in patients already initiated on dialysis. We used doppler method in the pre-dialysis assessments and ultra sound dilution technique after dialysis initiation.

Although not directly related to access creation, this study showed a significant increase in all-cause mortality within AVG group. This was similar to the findings in other studies showing the same increased trend of all-cause mortality with AVG or CVC [71, 72]. Numerous studies have also shown an increased risk of SSI with AVG [73, 74]. Infection was also the second commonest cause of death among patients dialyzing with AVG, after cardiac causes [75, 76]. Our results also showed a significant increase in SSI with the AVG group. However, contrary to other reports [57], we did not observe any significant increase in other morbidities such as haematoma, pseudo aneurysms or 'steal'. The management of an infected vascular access is always challenging. SSI in AAVF can often be successfully managed by oral or intravenous antibiotics alone while in AVG it often requires aggressive debridement or explantation [77].

\section{Conclusions}

- TBB-AVF shows excellent medium-term patency when constructed in a planned systematic manner. The primary, primary assisted, secondary and functional patency rates are comparable to AVG.

- A mature TBB-AVF gives comparable flow rate to an $\mathrm{AVG}$, thereby allowing adequate and satisfactory dialysis.

- Use of $\mathrm{AVG}$ is associated with a significantly increased all-cause mortality and SSI rate compared to TBB-AVF. Management of such SSI is often difficult, expensive and requires admission, explantation and prolonged intravenous antibiotics.

- Other access complications such as haematoma, pseudo aneurysms and distal 'steal' syndrome were comparable between TBB-AVF and AVG.

- The rate of re-interventions was comparable between the two groups.

\section{Limitations}

This was a single center study involving a single unit experience. Furthermore, only medium-term results were analysed at 6 months of follow-up. The nature of the study did not allow randomization or blinding. Despite the comparable baseline characteristics, selection bias could not be eliminated based on diameter of basilic veins and availability of prosthetic grafts. Although no significant difference among commercially available grafts has been demonstrated, a bigger study involving a wider array of prosthetic grafts may have been useful.

The numbers in the two groups were not comparable. Any potential difference in the outcomes between primary and staged transposition was not considered in the analysis although this has been widely investigated elsewhere. Other confounding variables such as patient age, presence of diabetes, underlying cause of ESKD were not included. An actual cost analysis could not be carried out due to the logistical limitations in a state-run free health care system. A patient satisfaction survey for access creation and comfort during haemodialysis as well as nurse satisfaction during needling was not performed. 


\section{Future directions}

Every effort should be made to construct an AAVF in preference to AVG. A prospective study undertaken to evaluate the relevant outcomes overcoming some of the above limitations would give more robust data allowing us to draw better conclusions. A longer follow up would also be useful in deciding the place of each of these vascular access modes for long term use. A proper costing structure accounting for material costs of grafts as well as operation costs for staged TBB-AVF and possible re-intervention would allow institutions to make additional recommendations on this area.

All authors disclose no conflict of interest. The study was conducted in accordance with the ethical standards of the relevant institutional or national ethics committee and the Helsinki Declaration of 1975, as revised in 2000 .

\section{References}

1. Aitken GR, Roderick PJ, Fraser S, Mindell JS, O'Donoghue D, Day J, et al. Change in prevalence of chronic kidney disease in England over time: comparison of nationally representative crosssectional surveys from 2003 to 2010. BMJ Open [Internet]. 2014 Jan;4(9):e005480.

Available from:

http://bmjopen.bmj.com/content/4/9/e005480.abstract

https://doi.org/10.1136/bmjopen-2014-005480

2. Varma PP. Prevalence of chronic kidney disease in India - Where are we heading? Indian J Nephrol. 2015;25(3):133-5. PMid:26060360 PMCid:PMC4446915

3. Coresh J, Selvin E, Stevens LA, Manzi J, Kusek JW, Eggers P, et al. Prevalence of chronic kidney disease in the United States. JAMA. 2007;298(17):2038-47.

https://doi.org/10.1001/jama.298.17.2038

PMid:17986697

4. White SL, Polkinghorne KR, Atkins RC, Chadban SJ. Comparison of the prevalence and mortality risk of CKD in Australia using the CKD Epidemiology Collaboration (CKD-EPI) and Modification of Diet in Renal Disease (MDRD) Study GFR estimating equations: Australian Diabetes, Obesity and Lifestyle. $\mathrm{Am} \mathrm{J}$ Kidney Dis. 2010;55(4):660-70.

https://doi.org/10.1053/j.ajkd.2009.12.011

PMid:20138414

5. Hoerger TJ, Simpson SA, Yarnoff BO, Pavkov ME, Rios Burrows $\mathrm{N}$, Saydah SH, et al. The future burden of CKD in the United States: A simulation model for the CDC CKD initiative. Am J Kidney Dis. 2015;65(3):403-11.

https://doi.org/10.1053/j.ajkd.2014.09.023

PMid:25468386

6 Zhang Q-L, Rothenbacher D. Prevalence of chronic kidney disease in population-based studies: systematic review. BMC Public Health. 2008;8:117.

https://doi.org/10.1186/1471-2458-8-117

PMid:18405348 PMCid:PMC2377260

7. Abecassis M, Bartlett ST, Collins AJ, Davis CL, Delmonico FL, Friedewald JJ, et al. Kidney transplantation as primary therapy for end-stage renal disease: a National Kidney Foundation/Kidney Disease Outcomes Quality Initiative (NKF/KDOQITM) conference. Clin J Am Soc Nephrol. 2008;3(2):471-80.

https://doi.org/10.2215/CJN.05021107

PMid:18256371 PMCid:PMC2390948
8. Delmonico FL, McBride MA. Analysis of the wait list and deaths among candidates waiting for a kidney transplant. Transplantation. 2008;86(12):1678-83.

https://doi.org/10.1097/TP.0b013e31818fe694

PMid:19104404

9. Collins AJ, Foley RN, Herzog C, Chavers B, Gilbertson D, Ishani A, et al. US renal data system 2012 annual data report. American Journal of Kidney Diseases. 2013;61(1 SUPPL.1).

https://doi.org/10.1053/j.ajkd.2012.11.031

10. KDOQI Advisory Board Members. NKF-K/DOQI Clinical Practice Guidelines. Vol. 48, American Journal of Kidney Diseases. 2006. p. 1-322.

11. Hemodialysis Adequacy 2006 Work Group. Clinical Practice Guidelines for Hemodialysis Adequacy, Update 2006. Am J Kidney Dis. 2006;48(5):S2-90.

PMid: 16813990

12. Rocco M, Daugirdas JT, Depner TA, Inrig J, Mehrotra R, Rocco M V., et al. KDOQI Clinical Practice Guideline for Hemodialysis Adequacy: 2015 Update. Am J Kidney Dis. 2015;66(5):884-930. https://doi.org/10.1053/j.ajkd.2015.07.015 PMid:26498416

13. Malovrh M. Primary vascular access: How can we do better? BANTAOJ.2012;10(1):11-2.

14. Vachharajani T. Atlas of dialysis vascular access. School of Medicine Wake Forest University [Internet]. 2010; Available from: http://www.renalsociety.org/RSAJ/journal/jul11/MartinezSmith.pdf

15. Noordzij M, Jager KJ, Van Der Veer SN, Kramar R, Collart F, Heaf $\mathrm{JG}$, et al. Use of vascular access for haemodialysis in Europe: A report from the ERA-EDTA Registry. Nephrol Dial Transplant. 2014;29(10):1956-64.

https://doi.org/10.1093/ndt/gfu253

PMid:25061126

16. Tordoir JHM, Keuter X, Planken N, de Haan MW, Van der Sande FM. Autogenous options in secondary and tertiary access for haemodialysis. Eur J Vasc Endovasc Surg. 2006 Jun;31(6):661-6. https://doi.org/10.1016/j.ejvs.2005.10.005 PMid:16297643

17. Levin N, Eknoyan G, Pipp M, Steinberg E. National Kidney Foundation: Dialysis Outcome Quality Initiative--development of methodology for clinical practice guidelines. Nephrol Dial Transpl. 1997;12(10):2060-3.

https://doi.org/10.1093/ndt/12.10.2060

18. Cawich SO, Jefferson D, Smith G, Hoeksema G, Iheonunekwu N, Hendriks F, et al. Cost-benefit comparison of hemodialysis access creation in a developing country and North American centres. Int JAngiol. 2010;19(1):e25-9.

https://doi.org/10.1055/s-0031-1278358

PMid:22477571 PMCid:PMC2949998

19. Leermakers JJPM, Bode AS, Vaidya A, Van der Sande FM, Evers SMAA, Tordoir JHM. Cost-effectiveness of vascular access for haemodialysis: arteriovenous fistulas versus arteriovenous grafts. Eur J Vasc Endovasc Surg. 2013;45(1):84-92.

https://doi.org/10.1016/j.ejvs.2012.10.012 PMid:23153926

20. Rosas SE, Feldman HI. Synthetic vascular hemodialysis access versus native arteriovenous fistula: a cost-utility analysis. Ann Surg. 2012;255(1):181-6.

https://doi.org/10.1097/SLA.0b013e31822f4e9b PMid:21918428 PMCid:PMC3243807

21. O'Hare AM, Dudley RA, Hynes DM, McCulloch CE, Navarro D, Colin P, et al. Impact of surgeon and surgical center characteristics on choice of permanent vascular access. Kidney Int. 2003;64(2):681-9. 
https://doi.org/10.1046/j.1523-1755.2003.00105.x PMid:12846766

22. Tan TW, Farber A. Brachial-basilic autogenous access. Semin Vasc Surg. 2011;24(2):63-71.

https://doi.org/10.1053/j.semvascsurg.2011.05.004 PMid:21889093

23. Shibutani S, Obara H, Ono S, Kakefuda T, Kitagawa Y Transposed brachiobasilic arteriovenous fistula. Ann Vasc Dis. 2013;6(2):164-8.

https://doi.org/10.3400/avd.oa.13-00042

PMid:23825496 PMCid:PMC3692985

24. Akoh JA, Paraskeva PP. Review of transposed basilic vein access for hemodialysis. J Vasc Access. 2015;16(5):356-63. https://doi.org/10.5301/jva.5000381

25. Korkut AK, Kosem M. Superficialization of the basilic vein technique in brachiobasilic arteriovenous fistula: surgical experience of 350 cases during 4 years period. Ann Vasc Surg. 2010;24(6):762-7.

https://doi.org/10.1016/j.avsg.2010.02.013

PMid:20471784

26. Bourquelot P, Karam L, Robert-Ebadi H, Pirozzi N. Transposition, elevation, lipectomy and V-Wing for easy needling. JVasc Access. 2015;16(Suppl 9):S108-13. https://doi.org/10.5301/jva.5000353

27. Hossny A. Brachiobasilic arteriovenous fistula: Different surgical techniques and their effects on fistula patency and dialysis-related complications. J Vasc Surg. 2003;37(4):821-6. https://doi.org/10.1067/mva.2003.181

28. Arroyo MR, Sideman MJ, Spergel L, Jennings WC. Primary and staged transposition arteriovenous fistulas. J Vasc Surg. 2008;47(6):1279-83.

https://doi.org/10.1016/j.jvs.2008.01.047

29. Kakkos SK, Haddad GK, Weaver MR, Haddad RK, Scully MM. Basilic Vein Transposition: What is the Optimal Technique? Eur J Vasc Endovasc Surg. 2010;39(5):612-9.

https://doi.org/10.1016/j.ejvs.2010.01.006

30. Lazarides MK, Georgiadis GS, Papasideris CP, Trellopoulos G, Tzilalis VD. Transposed brachial-basilic arteriovenous fistulas versus prosthetic upper limb grafts: A meta-analysis. Eur J Vasc Endovasc Surg. 2008;36(5):597-601.

https://doi.org/10.1016/j.ejvs.2008.07.008

31. Feldman HI, Kobrin S, Wasserstein A. Hemodialysis vascular access morbidity. J Am Soc Nephrol. 1996;7(4):523-35. PMid:8724885

32. Van Tricht I, De Wachter D, Tordoir J, Verdonck P. Hemodynamics and complications encountered with arteriovenous fistulas and grafts as vascular access for hemodialysis: A review. Ann Biomed Eng. 2005;33(9):1142-57. https://doi.org/10.1007/s10439-005-5367-X

33. Woo K, Doros G, Ng T, Farber A. Comparison of the efficacy of upper arm transposed arteriovenous fistulae and upper arm prosthetic grafts. J Vasc Surg. 2009;50(6):1405-11. https://doi.org/10.1016/j.jvs.2009.07.090

34. Marques G, Sadaghianloo N, Fouilhé L, Jean-Baptiste E, Declemy S, Clément $\mathrm{C}$, et al. Higher patency of transposed brachio-basilic arteriovenous fistulas compared to brachioaxillary grafts for hemodialysis patients. $J$ Vasc Access. 2015;16(6):486-92.

https://doi.org/10.5301/jva.5000433

35. Keuter XHA, De Smet AAEA, Kessels AGH, van der Sande FM, Welten RJTJ, Tordoir JHM. A randomized multicenter study of the outcome of brachial-basilic arteriovenous fistula and prosthetic brachial-antecubital forearm loop as vascular access for hemodialysis. J Vasc Surg. 2008;47(2):395-401. https://doi.org/10.1016/j.jvs.2007.09.063

36. Teodorescu V, Gustavson S, Schanzer H. Duplex ultrasound evaluation of hemodialysis access: A detailed protocol. Vol. 2012, International Journal of Nephrology. 2012:1-7

https://doi.org/10.1155/2012/508956

PMid:22848824 PMCid:PMC3400354

37. Raju S. PTFE grafts for hemodialysis access. Techniques for insertion and management of complications. Ann Surg. 1987;206(5):666-73.

https://doi.org/10.1097/00000658-198711000-00019

PMid:3675026 PMCid:PMC1493291

38. Patel PP, Altieri M, Jindal TR, Guy SR, Falta EM, Hurst FP, et al. Current Status of Synthetic and Biological Grafts for Hemodialysis. In: Hemodialysis - Different Aspects. 2011. p. 285-312.

39. Leaf DA, MacRae HS-H, Grant E, Kraut J. Isometric exercise increases the size of forearm veins in patients with chronic renal failure. Am J Med Sci. 2003;325(3):115-9. https://doi.org/10.1097/00000441-200303000-00003

40. Oder TF, Teodorescu V, Uribarri J. Effect of exercise on the diameter of arteriovenous fistulae in hemodialysis patients. ASAIOJ (American Soc Artif Intern Organs). 2003;49(5):554-5. https://doi.org/10.1097/01.MAT.0000084179.72533.DC

41. Polkinghorne K. Vascular access surveillance. Nephrology. 2008;13(SUPPL. 2):1-11. https://doi.org/10.1111/j.1440-1797.2008.00992.x

42. Sidawy AN, Gray R, Besarab A, Henry M, Ascher E, Silva M, et al. Recommended standards for reports dealing with arteriovenous hemodialysis accesses. J Vasc Surg. 2002;35(3):603-10 https://doi.org/10.1067/mva.2002.122025

43. Bacchini G, Cappello A, La Milia V, Andrulli S, Locatelli F. Color doppler ultrasonography imaging to guide transluminal angioplasty of venous stenosis. Kidney Int. 2000;58(4):1810-3. https://doi.org/10.1046/j.1523-1755.2000.00344.x

44. Bay WH, Henry ML, Lazarus JM, Lew NL, Ling J, Lowrie EG. Predicting hemodialysis access failure with color flow Doppler ultrasound. Am J Nephrol. 1998;18(4):296-304. https://doi.org/10.1159/000013354

45. Hoyt K, Hester FA, Bell RL, Lockhart ME, Robbin ML. Accuracy of volumetric flow rate measurements: an in vitro study using modern ultrasound scanners. J Ultrasound Med. 2009; 28 (11) : 1511-8. https://doi.org/10.7863/jum.2009.28.11.1511

46. Embree PM, O'Brien WD. Volumetric Blood Flow via TimeDomain Correlation: Experimental Verification. IEEE Trans Ultrason Ferroelectr Freq Control. 1990;37(3):176-89. https://doi.org/10.1109/58.55307

47. Krivitski NM. Theory and validation of access flow measurement by dilution technique during hemodialysis. Kidney Int. 1995;48(1):244-50. https://doi.org/10.1038/ki.1995.290

48. Dindo D, Demartines N, Clavien P-A. Classification of Surgical Complications. Ann Surg. 2004;240(2):205-13. https://doi.org/10.1097/01.sla.0000133083.54934.ae

49. Strasberg SM, Linehan DC, Hawkins WG. The Accordion Severity Grading System of Surgical Complications. Ann Surg. 2009;250(2):177-86. https://doi.org/10.1097/SLA.0b013e3181afde41

50. Schanzer H, Schwartz M, Harrington E, Haimov M. Treatment of ischemia due to "steal" by arteriovenous fistula with distal artery ligation and revascularization. J Vasc Surg. 1988;7(6):770-3.

https://doi.org/10.1067/mva.1988.avs0070770

https://doi.org/10.1016/0741-5214(88)90040-7 
51. Gradman WS, Pozrikidis C. Analysis of Options for Mitigating Hemodialysis Access-Related Ischemic Steal Phenomena. Ann Vasc Surg. 2004;18(1):59-65.

https://doi.org/10.1007/s10016-003-0103-1

PMid:14712381

52. Armonk NIC. IBM SPSS Statistics for Windows, Version 20.0. 2012.2011.

53. Lynch JR, Mohan S, McClellan WM. Achieving the goal: results from the Fistula First Breakthrough Initiative. Curr Opin Nephrol Hypertens. 2011;20(6):583-92.

https://doi.org/10.1097/MNH.0b013e32834b33c4

PMid:21897231

54. Vassalotti JA, Jennings WC, Beathard GA, Neumann M, Caponi $\mathrm{S}$, Fox $\mathrm{CH}$, et al. Fistula first breakthrough initiative: targeting catheter last in fistula first. Semin Dial. 2012;25(3):303-10.

https://doi.org/10.1111/j.1525-139X.2012.01069.x

PMid:22487024

55. Howard AD, Howard RS, Goldstein SL, Meyer KB. Fistula First Breakthrough Initiative (FFBI): lessons about arteriovenous fistula prevalence goals. Am J Kidney Dis. 2013;61(3):523-5.

https://doi.org/10.1053/j.ajkd.2012.09.014

PMid:23157938

56. Korepta LM, Watson JJ, Elder EA, Davis AT, Mansour MA, Chambers CM, et al. Outcomes for forearm and upper arm arteriovenous fistula creation with the transposition technique from a single institution. J Vasc Surg. 2016;63(3):764-71.

https://doi.org/10.1016/j.jvs.2015.09.049

PMid:26781074

57. Oliver MJ, McCann RL, Indridason OS, Butterly DW, Schwab SJ. Comparison of transposed brachiobasilic fistulas to upper arm grafts and brachiocephalic fistulas. Kidney Int. 2001;60(4):1532-9.

https://doi.org/10.1046/j.1523-1755.2001.00956.x

PMid: 11576369

58. Hemodialysis Adequacy 2006 Work Group. 2006 Updates Clinical Practice Guidelines and Recommendations Hemodialysis Adequacy Peritoneal Dialysis Adequacy. Am J Kidney Dis. 2006;48(5):S2-90.

PMid: 16813990

59. Al-Jaishi AA, Oliver MJ, Thomas SM, Lok CE, Zhang JC, Garg AX, et al. Patency Rates of the Arteriovenous Fistula for Hemodialysis: A\&nbsp; Systematic Review and Meta-analysis. Am J Kidney Dis. 2014;63(3):464-78. https://doi.org/10.1053/j.ajkd.2013.08.023

60. Dunlop MG, Mackinlay JY, McL Jenkins A. Vascular access: Experience with the brachiocephalic fistula. Ann R Coll Surg Engl. 1986;68(4):203-6.

PMid:3789606 PMCid:PMC2498388

61. Rivers SP, Scher LA, Sheehan E, Lynn R, Veith FJ. Basilic vein transposition: an underused autologous alternative to prosthetic dialysis angioaccess. J Vasc Surg. 1993;18(3):391-7. https://doi.org/10.1016/0741-5214(93)90256-L

62. El Mallah S. Staged basilic vein transposition for dialisys angioaccess. Int Angiol. 1998;17(2):65-8.

PMid:9754891

63. Woo K, Farber A, Doros G, Killeen K, Kohanzadeh S. Evaluation of the efficacy of the transposed upper arm arteriovenous fistula: a single institutional review of 190 basilic and cephalic vein transposition procedures. J Vasc Surg. 2007;46(1):94-100. https://doi.org/10.1016/j.jvs.2007.02.057

64. Allon M, Robbin ML. Increasing arteriovenous fistulas in hemodialysis patients: problems and solutions. Kidney Int. 2002;62(4):1109-24.

https://doi.org/10.1111/j.1523-1755.2002.kid551.x
65. Budu-Grajdeanu P, Schugart RC, Friedman A, Valentine C, Agarwal AK, Rovin BH. A mathematical model of venous neointimal hyperplasia formation. Theor Biol Med Model. 2008;5:2.

https://doi.org/10.1186/1742-4682-5-2

PMid:18215280 PMCid:PMC2263040

66. Almonacid PJ, Pallares EC, Rodriguez AQ, Valdes JS, Rueda Orgaz JA, Polo JR. Comparative study of use of Diastat versus standard wall PTFE grafts in upper arm hemodialysis access. Ann Vasc Surg. 2000;14(6):659-62.

https://doi.org/10.1007/s100169910117

PMid:11128463

67. Cook JW, Schuman ES, Standage BA, Heinl P. Patency and flow characteristics using stapled vascular anastomoses in dialysis grafts. Am J Surg. 2001;181(1):24-7.

https://doi.org/10.1016/S0002-9610(00)00547-X

68. Lin PH, Bush RL, Nelson JC, Lam R, Paladugu R, Chen C, et al. A prospective evaluation of interrupted nitinol surgical clips in arteriovenous fistula for hemodialysis. Am J Surg. 2003;186(6):625-30.

https://doi.org/10.1016/j.amjsurg.2003.08.007

PMid:14672769

69. Glickman MH, Stokes GK, Ross JR, Schuman ED, Sternbergh WC, Lindberg JS, et al. Multicenter evaluation of a polyurethaneurea vascular access graft as compared with the expanded polytetrafluoroethylene vascular access graft in hemodialysis applications. J Vasc Surg. 2001;34(3):465-73.

https://doi.org/10.1067/mva.2001.117330

PMid:11533599

70. Glickman MH. Arteriovenous Grafts. Semin Vasc Surg. 2011;24:108-12.

https://doi.org/10.1053/j.semvascsurg.2011.05.006 PMid:21889099

71. Dhingra RK, Young EW, Hulbert-Shearon TE, Leavey SF, Port FK. Type of vascular access and mortality in U.S. hemodialysis patients. Kidney Int. 2001;60(4):1443-51.

https://doi.org/10.1046/j.1523-1755.2001.00947.x PMid: 11576358

72. Polkinghorne KR, McDonald SP, Atkins RC, Kerr PG. Vascular access and all-cause mortality: a propensity score analysis. $J \mathrm{Am}$ Soc Nephrol. 2004;15(2):477-86. https://doi.org/10.1097/01.ASN.0000109668.05157.05

73. Lafrance J-P, Rahme E, Lelorier J, Iqbal S. Vascular access-related infections: definitions, incidence rates, and risk factors. $\mathrm{Am} \mathrm{J}$ Kidney Dis. 2008;52(5):982-93.

https://doi.org/10.1053/j.ajkd.2008.06.014

PMid:18760516

74. Nassar GM, Ayus JC. Infectious complications of the hemodialysis access. Kidney Int. 2001;60(1):1-13.

https://doi.org/10.1046/j.1523-1755.2001.00765.x PMid:11422731

75. Foundation NK. KDOQI Clinical Practice Guidelines and Clinical Practice Recommendations for 2006 Updates: Hemodialysis Adequacy, Peritoneal Dialysis Adequacy and Vascular Access. Am J Kidney Dis. 2006;48(suppl1):S1-409.

76. Gulati S, Sahu KM, Avula S, Sharma RK, Ayyagiri A, Pandey CM. Role of vascular access as a risk factor for infections in hemodialysis. Ren Fail. 2003;25(6):967-73. https://doi.org/10.1081/JDI-120026031

77.Tordoir J. 12 . Management of the infected vascular access. Nephrol Dial Transplant. 2007;22 (Suppl 1):88-117. 